Article

\title{
Facile Fabrication of a Low-Cost Alginate-Polyacrylamide Composite Aerogel for the Highly Efficient Removal of Lead Ions
}

\author{
Zhuqing Wang ${ }^{1}{ }^{\mathbb{D}}$, Qi Yang ${ }^{1}$, Xiuqin Zhao ${ }^{1}$ and Gang Wei ${ }^{2,3, *(\mathbb{C})}$ \\ 1 Anhui Key Laboratory of Photoelectric-Magnetic Functional Materials, Anhui Key Laboratory of Functional \\ Coordination Compounds, Anqing Normal University, Anqing 246133, China; \\ wangzhq@aqnu.edu.cn (Z.W.); wangmin08@aqnu.edu.cn (Q.Y.); anqingnu@gmail.com (X.Z.) \\ 2 College of Chemistry and Chemical Engineering, Qingdao University, Qingdao 266071, China \\ 3 Faculty of Production Engineering, University of Bremen, Bremen D-28359, Germany \\ * Correspondence: weigroup@qdu.edu.cn or wei@uni-bremen.de; Tel.: +86-150-6624-2101
}

Received: 26 October 2019; Accepted: 5 November 2019; Published: 7 November 2019

check for updates

\begin{abstract}
In this study, we demonstrate a one-step method for fabricating a novel sodium alginate-polyacrylamide (Alg-PAM) composite aerogel, which exhibits a very high affinity and selectivity towards $\mathrm{Pb}^{2+}$. The as-prepared Alg-PAM composite aerogel can uptake $99.2 \%$ of $\mathrm{Pb}^{2+}$ from $\mathrm{Pb}^{2+}$-containing aqueous solution $(0.1 \mathrm{mM})$ and the maximum adsorption capacity for $\mathrm{Pb}^{2+}$ reaches $252.2 \mathrm{mg} / \mathrm{g}$, which is higher than most of the reported $\mathrm{Pb}^{2+}$ adsorbents. Most importantly, the prepared Alg-PAM adsorbent can be regenerated through a simple acid-washing process with only a little loss of the adsorption performance after five adsorption-desorption cycles. In addition, the influence of the experimental conditions, such as the solution $\mathrm{pH}$, contact time, and temperature, on the adsorption performance of the Alg-PAM adsorbent was studied. It is clear that the low-cost raw materials, simple synthesis, regeneration ability, and highly efficient removal performance mean that the designed Alg-PAM aerogel has broad application potential in treating $\mathrm{Pb}^{2+}$-containing wastewater.
\end{abstract}

Keywords: wastewater; composite; aerogel; adsorbent; heavy metal ions

\section{Introduction}

Lead is widely used as a raw material in industrial production. Lead ions $\left(\mathrm{Pb}^{2+}\right)$ are often found in lead storage batteries, lead ore smelting, and recycled lead industrial wastewater [1]. $\mathrm{Pb}^{2+}$ in wastewater can be absorbed and enriched by aquatic animals and plants and then enter the human body through the food chain, thereby posing serious damage to the nerves, digestive systems, kidneys, and endocrine systems of humans [2,3]. Children are more sensitive to $\mathrm{Pb}^{2+}$ than adults, and excessive $\mathrm{Pb}^{2+}$ can cause mental decline and behavioral abnormalities among children $[4,5]$. Therefore, new methods and materials for effectively and selectively removing $\mathrm{Pb}^{2+}$ from wastewater must be developed.

Previously, many synthesized materials, such as one-dimensional (1D) nanofibers [6,7], two-dimensional (2D) films or membranes [3,8,9], and three-dimensional (3D) scaffolds [10-12], have been utilized as effective absorbents for treating $\mathrm{Pb}^{2+}$-containing water systems. $1 \mathrm{D}$ and $2 \mathrm{D}$ nano-adsorbents have a high adsorption capacity and adsorption rate for $\mathrm{Pb}^{2+}$ due to their high specific surface area and chemical activity, but the preparation of these nanomaterials usually requires stringent conditions, such as a high temperature, high pressure, high purity reagents, etc. In addition, these nano-adsorbent materials are difficult to recollect because of their small size. Macroscopic 3D porous material can overcome the above shortcomings. It not only provides a high surface area, but also facilitates solid-liquid separation. To achieve an economical use of the synthesized absorbents, an 
important aspect is to find low-cost and source-rich natural materials for fabricating various functional nanomaterials $[13,14]$.

Sodium alginate is a natural polysaccharide with an excellent biocompatibility and biodegradability. This molecule contains a large amount of carboxyl and hydroxyl functional groups that can complex metal ions [15]. Therefore, sodium alginate can also be used as a medical antidote for treating heavy metal ion poisoning [16]. However, alginate aerogels have poor mechanical properties. After repeated use, the aerogel structure can be easily destroyed, thereby resulting in an unstable adsorption capacity for heavy metal ions [17]. This kind of material shows improved mechanical properties given its special adhesion. In addition, the polyacrylamide molecule contains a large amount of amino groups that can chelate with metal ions, thereby adsorbing heavy metal ions in water $[18,19]$.

In this work, to improve the mechanical properties of alginate-based aerogel, we modified polyacrylamide on alginate salt by applying a simple chemical grafting technique and then prepared a novel sodium alginate/polyacrylamide (Alg-PAM) composite aerogel by applying the vacuum freeze-drying technique. We then used this aerogel to remove $\mathrm{Pb}^{2+}$ from wastewater, characterized its morphology and chemical composition, and studied its adsorption effect on $\mathrm{Pb}^{2+}$ under different experimental conditions.

\section{Materials and Methods}

\subsection{Chemicals and Materials}

Sodium alginate (low viscosity), polyacrylamide, nitric acid $\left(\mathrm{HNO}_{3}\right)$, sodium hydroxide $(\mathrm{NaOH})$, metal salts, 1-Ethyl-3-(3-dimethyllaminopropyl)carbodiimide hydrochloride, and N-hydroxysuccinimide were purchased from the Shanghai Aladdin Reagent Company (Shanghai, China). All metal salt solutions were prepared by using ultrapure water. The $\mathrm{pH}$ value of the solution was adjusted with $1.0 \mathrm{M} \mathrm{HNO}_{3}$ or $\mathrm{NaOH}$. Lake water was taken from the Anqing Lianhu Lake (Anqing, China), whereas river water was collected from the Anqing section of the Yangtze River (Anqing, China).

\subsection{Apparatus}

Macroscopic and microscopic images of the materials were taken using a D600 Canon digital camera and Quanta 250FEG scanning electron microscopes (SEM, FEI Company, Hillsboro, Oregon, USA), respectively. The chemical composition of the adsorbent and the functional groups contained therein were determined using an Avatar 360 infrared spectrometer (Thermo Nicolet Corporation, Waltham, Massachusetts, USA) and Axis Ultra DLD X-ray photoelectron spectrometer (XPS, Shimadzu Corporation, Tokyo, Japan). A JJ-1 electric agitator (Changzhou Guohua Company, Changzhou, China) and MS7-H550-Pro agitator (Dragon Laboratory Instruments Limited, Beijing, China) were used for mechanical and magnetic stirring, respectively. A PHS-3E acidity meter (Shanghai Leici Company, Shanghai, China) was used to determine the $\mathrm{pH}$ value of the solution. Each adsorption/desorption experiment was conducted three times in parallel, and the concentration of each metal ion in the solution was measured by an Optima 8000 inductively coupled plasma optical emission spectrometer (ICP-OES, PerkinElmer Instrument Co., Ltd, Waltham, MA, USA).

\subsection{Preparation of the Sodium Alginate-polyacrylamide (Alg-PAM) Composite Aerogel}

First, $2.0 \mathrm{~g}$ of sodium alginate was weighed and dissolved in $98.0 \mathrm{~mL}$ of ultrapure water. Second, $0.15 \mathrm{~g}$ of 1-Ethyl-3-(3-dimethyllaminopropyl)carbodiimide hydrochloride and $0.12 \mathrm{~g}$ of $\mathrm{N}$-hydroxysuccinimide were added to the solution and mechanically stirred for 3 hours. Third, $2.0 \mathrm{~g}$ of polyacrylamide was added to the mixture, and stirring was continued for 12 hours at room temperature. Fourth, under magnetic stirring, the mixture was dropped into a calcium nitrate solution (when the mixture was in contact with the $\mathrm{Ca}^{2+}$ solution $(0.5 \mathrm{M})$, an oval hydrogel was immediately formed), and the hydrogels were then collected by filtration and washed thrice with ultrapure water. Fifth, the 
hydrogels were immersed in ultrapure water, placed in a vacuum freeze-drying apparatus, frozen for 4 hours, and vacuum dried for 20 hours to obtain the sodium alginate-polyacrylamide (Alg-PAM) composite aerogel.

\subsection{Adsorption and Desorption Tests}

In an adsorption experiment, about $100 \mathrm{mg}$ of $\mathrm{Alg}$-PAM was weighed and added to $40 \mathrm{~mL}$ of the $0.1 \mathrm{mM} \mathrm{Pb}^{2+}$ (or other metal ions) solution, stirred at room temperature for 24 hours, and eventually filtered through filter paper and a funnel at atmospheric pressure. The amount of $\mathrm{Pb}^{2+}$ remaining in the filtrate was measured using the ICP-OES.

In a desorption experiment, $\mathrm{Pb}^{2+}$-loaded $\mathrm{Alg}-\mathrm{PAM}$ was immersed in $40 \mathrm{~mL}$ of the $0.05 \mathrm{M} \mathrm{HNO}_{3}$ solution for 30 minutes, filtered, and washed thrice with ultrapure water, and the amount of $\mathrm{Pb}^{2+}$ in the eluate was then determined using ICP-OES.

\section{Results and Discussion}

\subsection{Material Characterization}

In order to determine the components and functional groups contained in the prepared Alg-PAM, we characterized the raw sodium alginate, polyacrylamide, and Alg-PAM composite aerogel by infrared spectroscopy. As shown in Figure 1, in the three spectra, the absorption peaks around 2925 $\mathrm{cm}^{-1}$ are aliphatic $\mathrm{C}-\mathrm{H}$ stretching vibrations. In the spectrum of sodium alginate, the broad absorption peak near $3400 \mathrm{~cm}^{-1}$ is $-\mathrm{OH}$ stretching vibration, and the absorption peak at $1412 \mathrm{~cm}^{-1}$ belongs to the $-\mathrm{COO}^{-}$group [20]. In the spectrum of polyacrylamide, the absorption peak at $1650 \mathrm{~cm}^{-1}$ can be assigned to the amide bond [21]. Compared with the spectrum of sodium alginate, a new peak of the amide bond is observed near $1650 \mathrm{~cm}^{-1}$ in Alg-PAM, thereby suggesting that polyacrylamide was successfully modified on the calcium alginate aerogel [20]. Furthermore, we also characterized the XPS spectra of Alg-PAM before and after $\mathrm{Pb}^{2+}$ adsorption. As shown in Figure 2, after adsorption, new $\mathrm{Pb}$ 4f peaks could be observed on the Alg-PAM adsorbent, thereby indicating that $\mathrm{Pb}^{2+}$ ions were successfully loaded onto the Alg-PAM adsorbent [22].

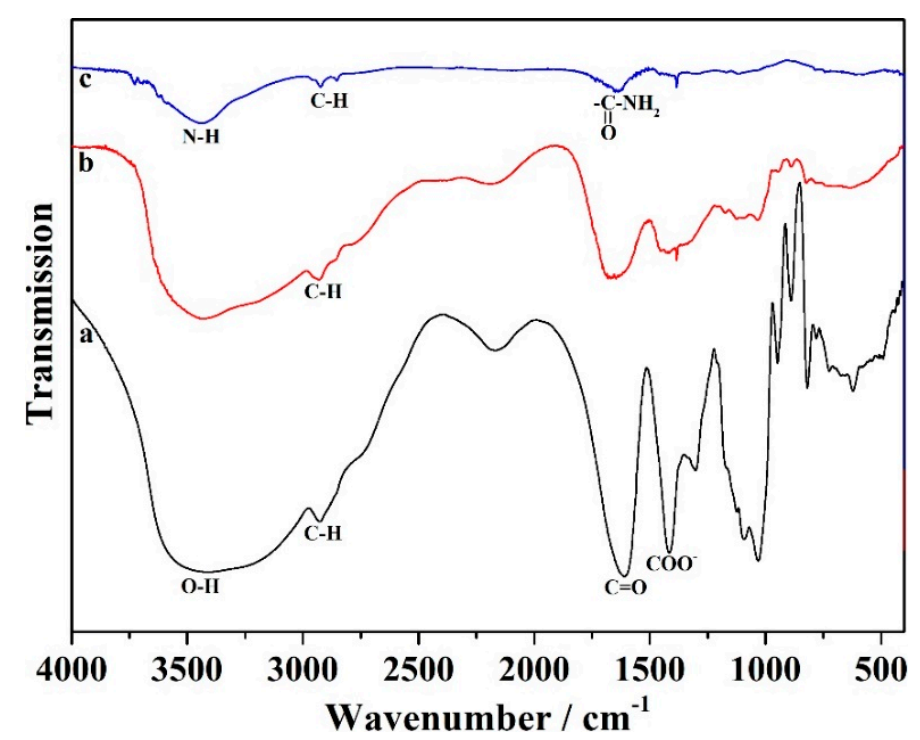

Figure 1. Infrared spectra of (a) raw sodium alginate, (b) alginate/polyacrylamide composite aerogel (Alg-PAM), and (c) raw polyacrylamide. 


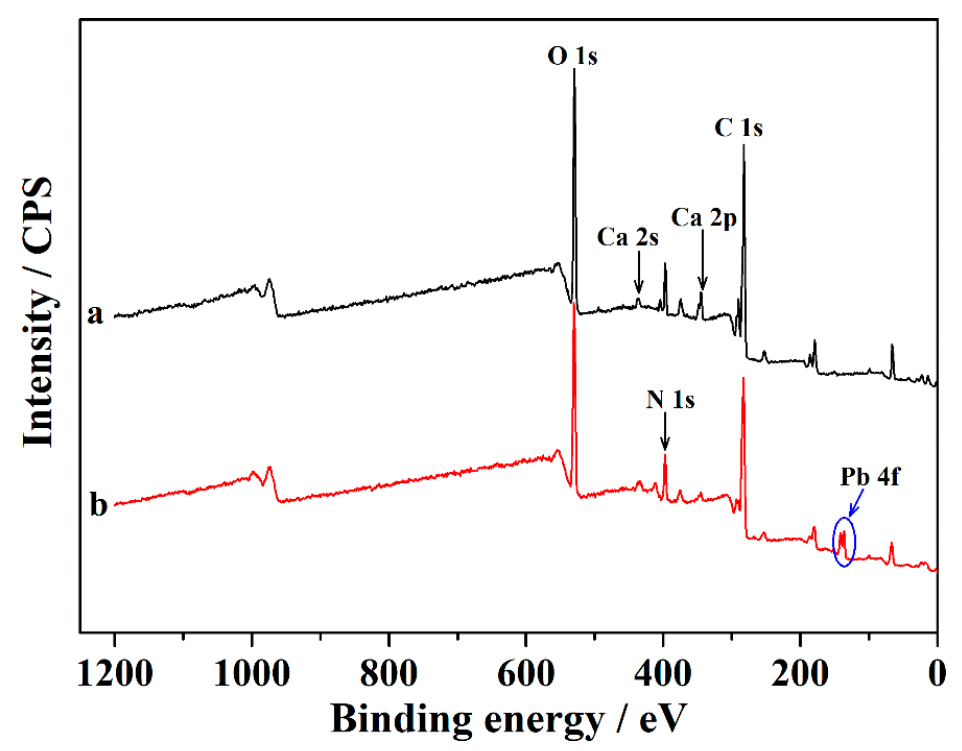

Figure 2. X-ray photoelectron spectrometer (XPS) spectra of sodium alginate-polyacrylamide (Alg-PAM)

(a) before and (b) after $\mathrm{Pb}^{2+}$ adsorption.

Moreover, we also characterized the morphology of Alg-PAM. As shown in Figure 3, the as-prepared Alg-PAM takes the form of white aerogel balls in the shape of water droplets. When amplified locally, many wrinkles can be seen on the Alg-PAM surface. This wrinkled surface can increase the contact area between the adsorbent and adsorbate, thereby increasing the adsorption capacity of Alg-PAM to the target metal ions.
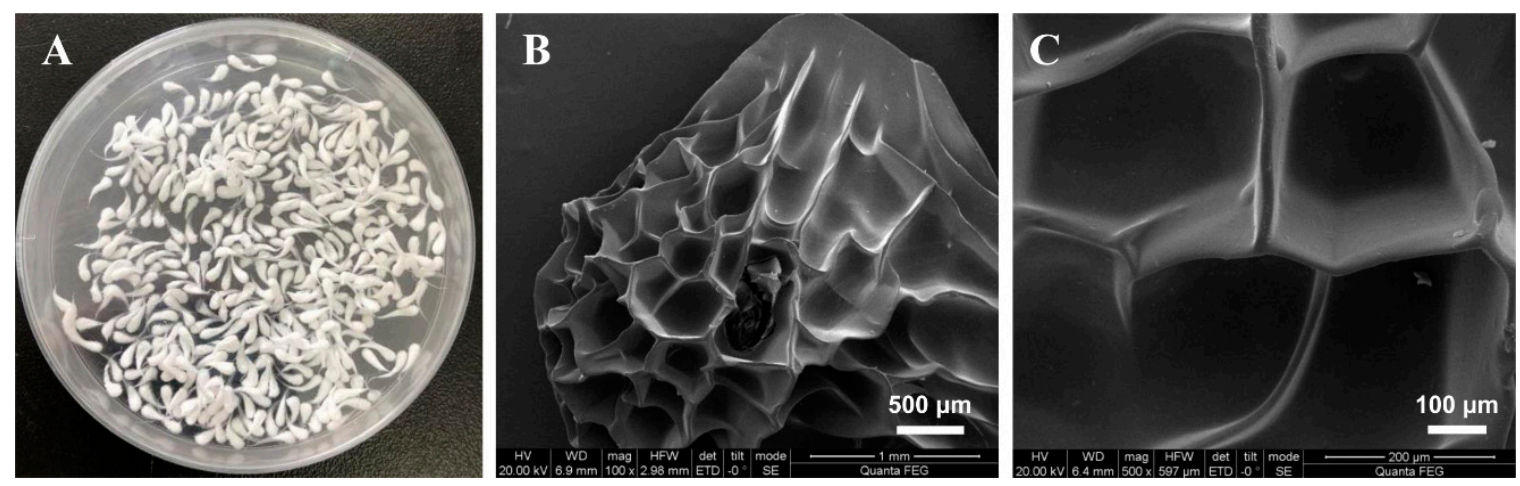

Figure 3. (A) Digital photograph of Alg-PAM; (B) Scanning electron microscope (SEM) Image of Alg-PAM; and (C) partial enlargement of (B).

\subsection{Effect of Solution $\mathrm{pH}$}

In order to investigate the effect of solution acidity on the adsorption performance of Alg-PAM, $\sim 100 \mathrm{mg}$ of Alg-PAM adsorbent was added to $40 \mathrm{~mL} \mathrm{pH}=1,2,3,4,5$, or $6 \mathrm{of} \mathrm{Pb}^{2+}(0.1 \mathrm{mM})$ solution. After stirring for 24 hours and filtration, the concentration of $\mathrm{Pb}^{2+}$ in the filtrate was measured by ICP-OES. The experimental results are shown in Figure 4. When the $\mathrm{pH}$ value of the solution is 1, Alg-PAM can only remove $17.7 \%$ of $\mathrm{Pb}^{2+}$ in wastewater, which may be ascribed to the fact that the carboxyl and amino groups on Alg-PAM are protonated in the strongly acidic environment, thereby reducing the functional groups bound to $\mathrm{Pb}^{2+}$ [23]. When the $\mathrm{pH}$ value of the solution is within the range of 3 to 6 , Alg-PAM can remove more than $99.0 \% \mathrm{of} \mathrm{Pb}^{2+}$ in wastewater. When the $\mathrm{pH}$ value of the solution exceeds 6 , according to the solubility product rule, the $\mathrm{Pb}^{2+}$ in the solution begins to form a $\mathrm{Pb}(\mathrm{OH})_{2}$ precipitate. Therefore, the optimum $\mathrm{pH}$ value of the adsorbed solution ranges between 3 
and 6. Within this range, neither the amino group nor the carboxyl group is protonated, and the $\mathrm{Pb}^{2+}$ in the solution does not form a $\mathrm{Pb}(\mathrm{OH})_{2}$ precipitate.

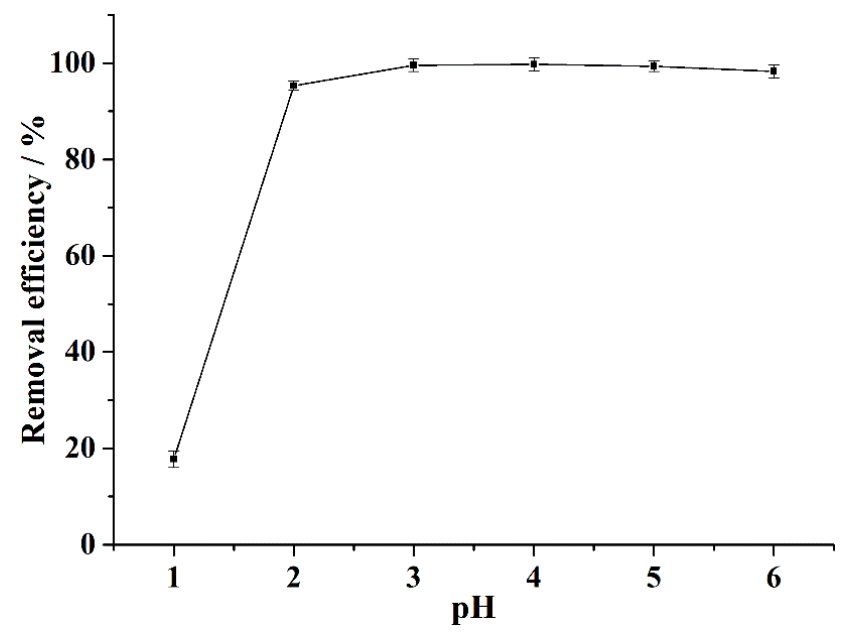

Figure 4. Influence of the solution acidity on the $\mathrm{Pb}^{2+}$ removal efficiency of Alg-PAM.

\subsection{Effect of Adsorption Time}

Approximately $100 \mathrm{mg}$ of Alg-PAM was weighed and added to $40 \mathrm{~mL}$ of the $0.1 \mathrm{mM} \mathrm{Pb}^{2+}$ solution; stirred for $0.5,1,2,3,6,12,20,24,30$, or 36 hours; and then filtered. The amount of $\mathrm{Pb}^{2+}$ remaining in the filtrate was determined by ICP-OES. As can be seen in Figure 5, as the contact time increases, the amount of $\mathrm{Pb}^{2+}$ adsorbed by Alg-PAM initially increases, followed by a gradual increase, and eventually reaches stability. When the adsorption time is 12 hours, Alg-PAM can remove $97.6 \%$ of $\mathrm{Pb}^{2+}$ in the solution. When the adsorption time is 24 hours, Alg-PAM can remove $99.2 \%$ of $\mathrm{Pb}^{2+}$ in the solution. When the adsorption time is longer than 24 hours, the $\mathrm{Pb}^{2+}$ removal efficiency of Alg-PAM remains stable. Therefore, the adsorption time we selected in this study was 24 hours, which is close to the reported values in the literature [24,25].

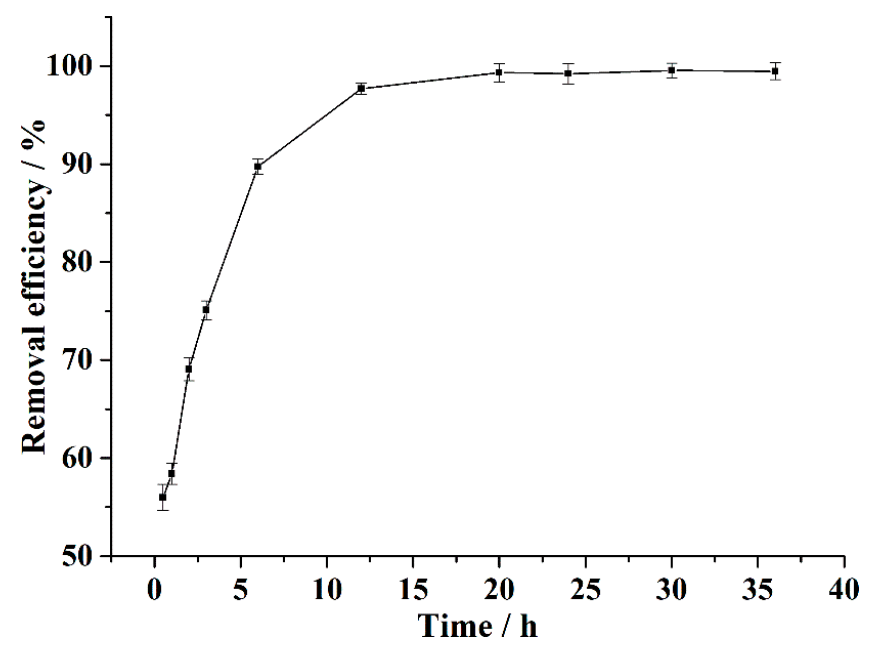

Figure 5. Effect of the contact time on the removal efficiency of Alg-PAM for $\mathrm{Pb}^{2+}$.

\subsection{Influence of Temperature}

We also studied the removal efficiency of Alg-PAM for $\mathrm{Pb}^{2+}$ at different ambient temperatures. About $100 \mathrm{mg}$ of Alg-PAM was weighed and added to $40 \mathrm{~mL}$ of the $0.1 \mathrm{mM} \mathrm{Pb}^{2+}$ solution, placed at $0,5,15,20,30,40$, or $50{ }^{\circ} \mathrm{C}$ for 24 hours, and filtered, and the amount of $\mathrm{Pb}^{2+}$ remaining in the filtrate was then measured by ICP-OES. Figure 6 shows that the $\mathrm{Pb}^{2+}$ removal efficiency of Alg-PAM 
gradually increases along with ambient temperature. When the ambient temperature is $15^{\circ} \mathrm{C}$, the adsorption efficiency of $\mathrm{Pb}^{2+}$ by Alg-PAM is $94.9 \%$. When the temperature increases to $40{ }^{\circ} \mathrm{C}$, the removal efficiency reaches $99.3 \%$. These experimental results are similar to the reported literature and indicate that the process by which Alg-PAM binds to $\mathrm{Pb}^{2+}$ is endothermic $[26,27]$.

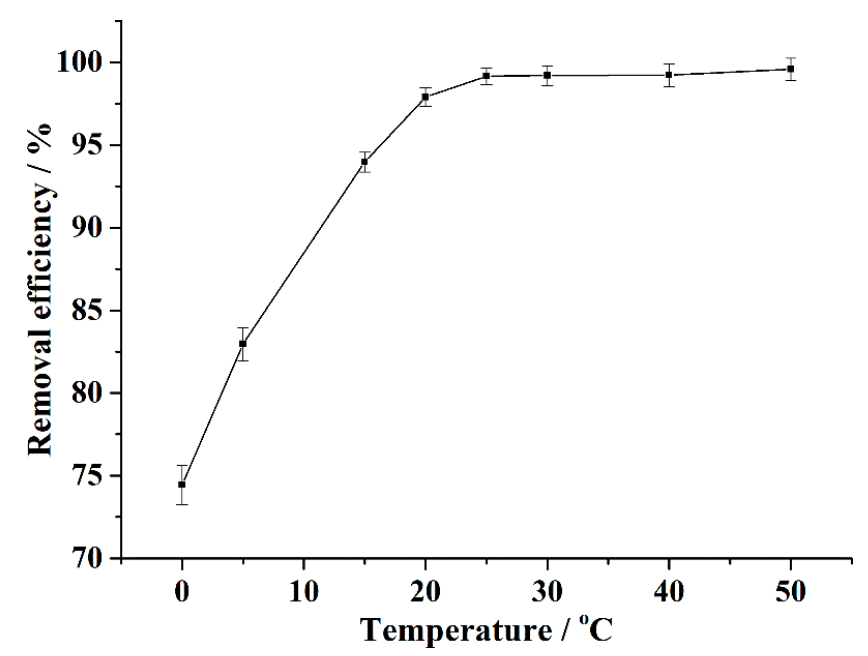

Figure 6. Removal efficiency of Alg-PAM for $\mathrm{Pb}^{2+}$ at different ambient temperatures.

\subsection{Adsorption Performance of Alg-PAM for Metal Ions}

The adsorption abilities of Alg-PAM for different metal ions (such as $\mathrm{Pb}^{2+}, \mathrm{Cu}^{2+}, \mathrm{Cr}^{3+}, \mathrm{Cd}^{2+}$, $\mathrm{Zn}^{2+}$, and $\mathrm{Co}^{2+}$ ) are shown in Table 1. It can be seen from Table 1 that Alg-PAM has a high affinity for $\mathrm{Pb}^{2+}, \mathrm{Cu}^{2+}$, and $\mathrm{Cd}^{2+}$, and can remove more than $90 \%$ of the corresponding metal ions in the solution, which may be attributed to the carboxyl, hydroxyl, and amino groups on Alg-PAM that bind the metal ions via a coordination effect. In addition, despite the coexistence of $\mathrm{Cu}^{2+}, \mathrm{Cr}^{3+}, \mathrm{Cd}^{2+}, \mathrm{Zn}^{2+}$, or $\mathrm{Co}^{2+}$, Alg-PAM can still remove more than $95 \%$ of $\mathrm{Pb}^{2+}$ in the mixed solution, and the relative selectivity coefficients $(k)$ are all over 8 . This indicates that the prepared Alg-PAM has a higher selectivity for $\mathrm{Pb}^{2+}$, and can selectively remove $\mathrm{Pb}^{2+}$ in the presence of other ions.

Table 1. Adsorption ability of the sodium alginate-polyacrylamide (Alg-PAM) for different metal ions.

\begin{tabular}{|c|c|c|c|c|c|c|c|c|c|}
\hline Alg-PAM & \multicolumn{2}{|c|}{ Initial Solution (mM) } & \multicolumn{2}{|c|}{ Removal Efficiency (\%) } & \multicolumn{2}{|c|}{ Adsorption Capacity (mg/g) } & \multicolumn{2}{|c|}{$\mathbf{K}_{\mathrm{d}}$} & $k$ \\
\hline \multirow{7}{*}{$\begin{array}{l}\text { In ultrapure } \\
\text { water }\end{array}$} & $0.1\left(\mathrm{Cu}^{2+}\right)$ & - & 91.6 & - & 2.3 & - & 4.4 & - & - \\
\hline & $0.1\left(\mathrm{Cd}^{2+}\right)$ & - & 90.2 & - & 4.1 & - & 3.7 & - & - \\
\hline & $0.1\left(\mathrm{Zn}^{2+}\right)$ & - & 76.9 & - & 2.0 & - & 1.3 & - & - \\
\hline & $0.1\left(\mathrm{Co}^{2+}\right)$ & - & 69.5 & - & 1.6 & - & 0.9 & - & - \\
\hline & $0.1\left(\mathrm{~Pb}^{2+}\right)$ & $0.1\left(\mathrm{Cd}^{2+}\right)$ & 96.7 & 66.0 & 8.0 & 3.0 & 11.7 & 0.8 & 15.1 \\
\hline & $0.1\left(\mathrm{~Pb}^{2+}\right)$ & $0.1\left(\mathrm{Zn}^{2+}\right)$ & 97.8 & 61.9 & 8.1 & 1.6 & 17.8 & 0.6 & 27.3 \\
\hline & $0.1\left(\mathrm{~Pb}^{2+}\right)$ & $0.1\left(\mathrm{Co}^{2+}\right)$ & 97.1 & 43.2 & 8.0 & 1.0 & 13.4 & 0.3 & 44.0 \\
\hline In lake water & $0.1\left(\mathrm{~Pb}^{2+}\right)$ & - & 88.4 & - & 7.3 & - & 3.1 & - & - \\
\hline In river water & $0.1\left(\mathrm{~Pb}^{2+}\right)$ & - & 94.3 & - & 7.8 & - & 6.6 & - & - \\
\hline
\end{tabular}

In order to confirm the maximum adsorption capacity of the Alg-PAM adsorbent for $\mathrm{Pb}^{2+}$, we added $100 \mathrm{mg}$ of Alg-PAM to $40 \mathrm{~mL}$ of different concentrations of $\mathrm{Pb}^{2+}$ solution, stirred for 24 hours, filtered, and then measured the amount of $\mathrm{Pb}^{2+}$ remaining in the filtrate. It can be seen from Figure 7 that as the solution concentration increases, the adsorption capacity of $\mathrm{Alg}-\mathrm{PAM}$ for $\mathrm{Pb}^{2+}$ gradually increases. When the $\mathrm{Pb}^{2+}$ concentration increases from 0.1 to $50 \mathrm{mM}$, the adsorption capacity of $\mathrm{Alg}-\mathrm{PAM}$ for $\mathrm{Pb}^{2+}$ rapidly increases from 8.2 to $252.2 \mathrm{mg} / \mathrm{g}$. However, when the concentration of $\mathrm{Pb}^{2+}$ 
exceeds $50 \mathrm{mM}$, the adsorption capacity of Alg-PAM remains stable and shows no further increase. Therefore, the maximum adsorption capacity of Alg-PAM for $\mathrm{Pb}^{2+}$ is $252.2 \mathrm{mg} / \mathrm{g}$, which is higher than that of most of the reported $\mathrm{Pb}^{2+}$ sorbents (Table 2) [28-41].

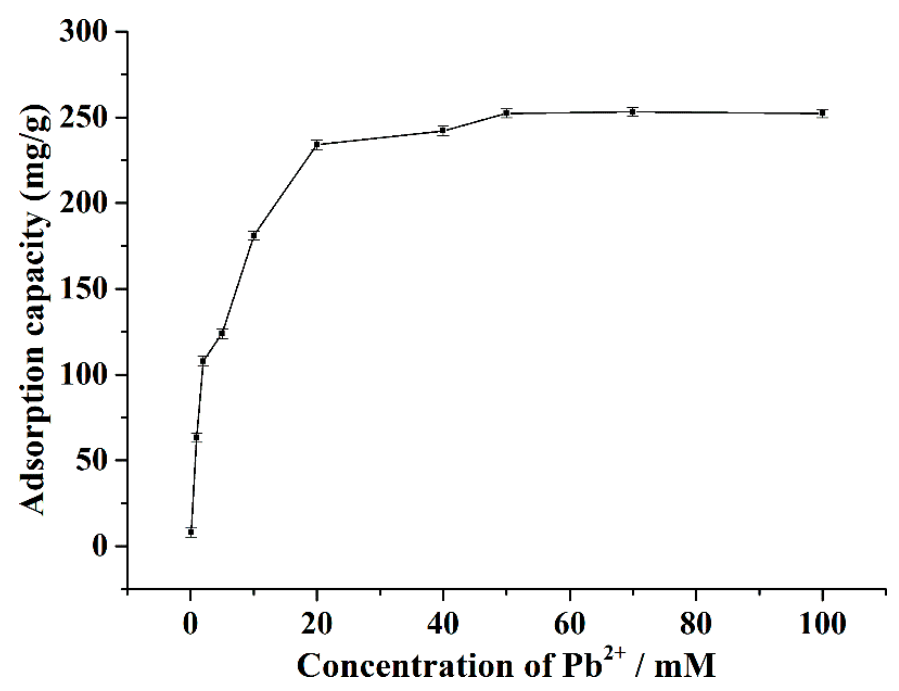

Figure 7. Maximum adsorption capacity of the Alg-PAM for $\mathrm{Pb}^{2+}$.

Table 2. Adsorption capacities of the reported adsorbents for $\mathrm{Pb}^{2+}$.

\begin{tabular}{cccc}
\hline Adsorbents & Adsorbate & Maximum Adsorption Capacity $(\mathbf{m g} / \mathbf{g})$ & References \\
\hline Polyampholyte hydrogel & $\mathrm{Pb}^{2+}, \mathrm{Cd}^{2+}$ & $216.1\left(\mathrm{~Pb}^{2+}\right), 153.8\left(\mathrm{Cd}^{2+}\right)$ & {$[28]$} \\
Nanohydroxyapatite & $\mathrm{Pb}^{2+}$ & 200.0 & {$[29]$} \\
$\mathrm{GO}^{1}$ & $\mathrm{~Pb}^{2+}$ & 178.5 & {$[30]$} \\
GO/chitosan/FeOOH & $\mathrm{Pb}^{2+}$ & 111.1 & {$[31]$} \\
Thiol-functionalized GO & $\mathrm{Pb}^{2+}$ & 200.0 & {$[32]$} \\
Dithiocarbamate-functionalized GO & $\mathrm{Pb}^{2+}$ & 132.0 & {$[33]$} \\
Xanthate-modified thiourea & $\mathrm{Pb}^{2+}$ & 188.1 & {$[34]$} \\
chitosan sponge & $\mathrm{Pb}^{2+}, \mathrm{Cd}^{2+}, \mathrm{Cu}^{2+}$ & $153.1\left(\mathrm{~Pb}^{2+}\right), 28.1\left(\mathrm{Cd}^{2+}\right), 34.2\left(\mathrm{Cu}^{2+}\right)$ & {$[35]$} \\
Biochar & $\mathrm{Pb}^{2+}$ & 189.9 & {$[36]$} \\
Amino-functionalized wood flour & $\mathrm{Pb}^{2+}$ & 125.0 & {$[37]$} \\
GO & $\mathrm{Pb}^{2+}$ & 138.9 & {$[38]$} \\
Chitosan-poly(acrylic acid) & $\mathrm{Pb}^{2+}$ & 70.0 & {$[39]$} \\
composite beads & $\mathrm{Pb}^{2+}$ & 99.8 & {$[40]$} \\
Titanium-Tin oxide nanocomposite & $\mathrm{Pb}^{2+}, \mathrm{Cu}^{2+}$ & {$[41]$} \\
Nitrogen-doped carbon & $\mathrm{Pb}^{2+}$ & $55.5\left(\mathrm{~Pb}^{2+}\right), 68.7\left(\mathrm{Cu}^{2+}\right)$ & Our work \\
nanospheroids & \multicolumn{2}{c}{252.2} &
\end{tabular}

\subsection{Regeneration of Alg-PAM}

Under acidic conditions, $\mathrm{H}$ protons can displace $\mathrm{Pb}^{2+}$ ions that are attached to the carboxyl, hydroxyl, and amino groups of the Alg-PAM [42]. To avoid introducing other impurity ions, we used $\mathrm{HNO}_{3}$ as an eluent to regenerate the adsorbent in this study. In the adsorbent regeneration experiment, the $\mathrm{Pb}^{2+}$-loaded Alg-PAM was immersed in $40 \mathrm{~mL}$ of the $0.05 \mathrm{M} \mathrm{HNO}_{3}$ solution for 30 minutes and filtered, and the adsorbent was washed successively with ultrapure water, saturated $\mathrm{Ca}(\mathrm{OH})_{2}$ solution, and ultrapure water. The adsorbent was then dried in an oven at $40{ }^{\circ} \mathrm{C}$ for 4 hours to obtain the regenerated Alg-PAM. It can be seen from Figure 8 that the regenerated Alg-PAM adsorbent has stable chemical properties, and its removal efficiency for $\mathrm{Pb}^{2+}$ is in the range of $97 \pm 3 \%$. In addition, the physical morphology of Alg-PAM also remains stable after five adsorption-desorption cycles. 


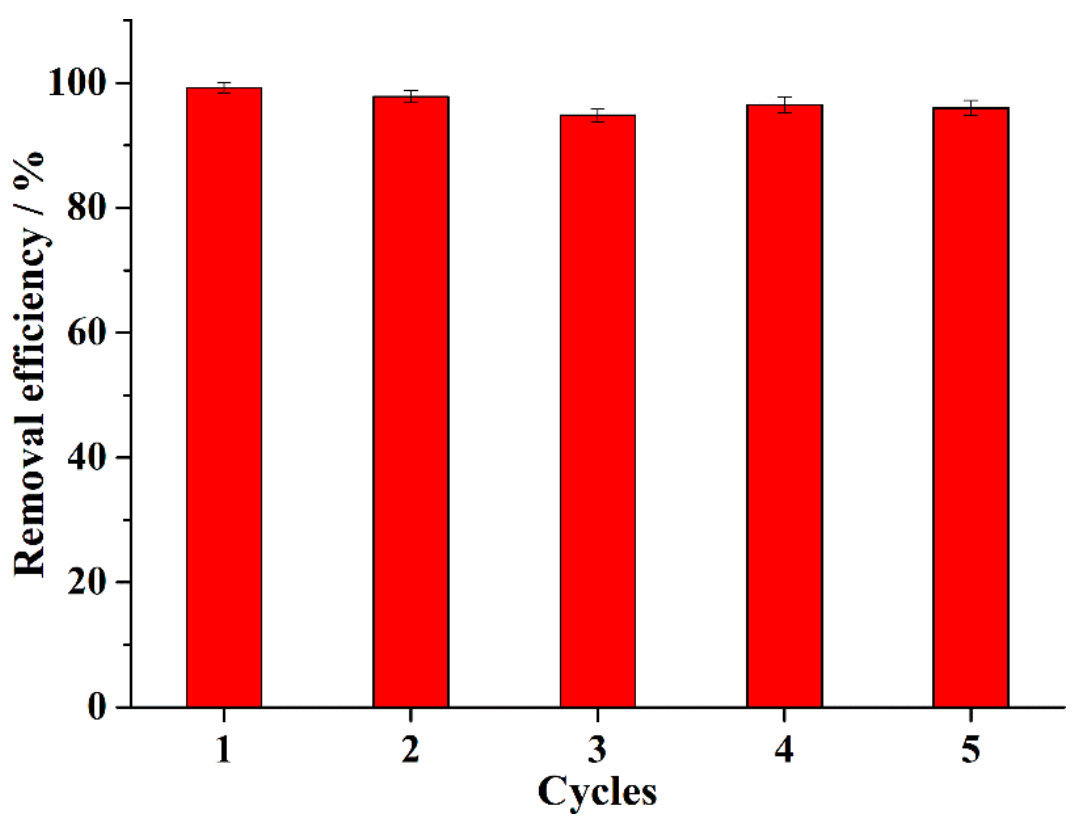

Figure 8. Removal efficiency of $\mathrm{Pb}^{2+}$ by $\mathrm{Alg}-\mathrm{PAM}$ in five adsorption-desorption cycles.

\section{Conclusions}

We successfully prepared a novel sodium alginate-polyacrylamide composite aerogel (Alg-PAM) by using a simple one-step synthesis method. The prepared Alg-PAM is a macroscopic adsorbent that can be easily applied for solid-liquid separation. Alg-PAM also exhibits a high affinity and selectivity for $\mathrm{Pb}^{2+}$ due to the carboxyl, hydroxyl, and amide groups and can remove $99.2 \%$ of $\mathrm{Pb}^{2+}$ from wastewater with a maximum adsorption capacity up to $252.2 \mathrm{mg} / \mathrm{g}$. This adsorbent can be regenerated by simple acid washing, and its adsorption performance remains stable after repeated use. Given its use of low-cost and green raw materials, its simple preparation process, and its high efficiency removal performance, Alg-PAM has broad application potential in treating heavy metal ions in wastewater.

Author Contributions: Z.W. conceived and designed the experiments; Q.Y. performed the experiments; Q.Y. and X.Z. analyzed the data; Z.W. and G.W. wrote the paper; G.W. revised the manuscript.

Funding: This research was funded by the Anhui Department of Education, grant number gxyZD2019045.

Conflicts of Interest: The authors declare no conflicts of interest.

\section{References}

1. Camizuli, E.; Scheifler, R.; Garnier, S.; Monna, F.; Losno, R.; Gourault, C.; Hamm, G.; Lachiche, C.; Delivet, G.; Chateau, C.; et al. Trace metals from historical mining sites and past metallurgical activity remain bioavailable to wildlife today. Sci. Rep. 2018, 8, 3436. [CrossRef]

2. Hansson, S.V.; Grusson, Y.; Chimienti, M.; Claustres, A.; Jean, S.; Le Roux, G. Legacy Pb pollution in the contemporary environment and its potential bioavailability in three mountain catchments. Sci. Total Environ. 2019, 671, 1227-1236. [CrossRef]

3. Wang, Z.Q.; Wu, A.G.; Ciacchi, L.C.; Wei, G. Recent advances in nanoporous membranes for water purification. Nanomaterials 2018, 8, 65. [CrossRef]

4. Cundy, A.B.; Croudace, I.W. The fate of contaminants and stable Pb isotopes in a changing estuarine environment: 20 years on. Environ. Sci. Technol. 2017, 51, 9488-9497. [CrossRef]

5. Li, K.T.; Wu, G.H.; Wang, M.; Zhou, X.H.; Wang, Z.Q. Efficient removal of lead ions from water by a low-cost alginate-melamine hybrid sorbent. Appl. Sci. 2018, 8, 1518. [CrossRef]

6. Li, Y.; Qiu, T.B.; Xu, X.Y. Preparation of lead-ion imprinted crosslinked electro-spun chitosan nanofiber mats and application in lead ions removal from aqueous solutions. Eur. Polym. J. 2013, 49, 1487-1494. [CrossRef] 
7. Chakraborty, A.; Deva, D.; Sharma, A.; Verma, N. Adsorbents based on carbon microfibers and carbon nanofibers for the removal of phenol and lead from water. J. Colloid Interf. Sci. 2011, 359, 228-239. [CrossRef]

8. Tao, Y.G.; Ye, L.B.; Pan, J.; Wang, Y.M.; Tang, B. Removal of Pb(II) from aqueous solution on chitosan/TiO 2 hybrid film. J. Hazard. Mater. 2009, 161, 718-722. [CrossRef]

9. Han, Y.; Xu, Z.; Gao, C. Ultrathin graphene nanofiltration membrane for water purification. Adv. Funct. Mater. 2013, 23, 3693-3700. [CrossRef]

10. Ragnini, C.A.R.; Di Iglia, R.A.; Bizzo, W.; Bertazzoli, R. Recycled niobium felt as an efficient three-dimensional electrode for electrolytic metal ion removal. Water Res. 2000, 34, 3269-3276. [CrossRef]

11. Gao, F.F.; Du, X.; Hao, X.G.; Li, S.S.; Zheng, J.L.; Yang, Y.Y.; Han, N.C.; Guan, G.Q. A potential-controlled ion pump based on a three-dimensional PPy@GO membrane for separating dilute lead ions from wastewater. Electrochim. Acta 2017, 236, 434-442. [CrossRef]

12. Wang, Y.; Guo, L.; Qi, P.F.; Liu, X.M.; Wei, G. Synthesis of three-dimensional graphene-based hybrid materials for water purification: A review. Nanomaterials 2019, 9, 1123. [CrossRef]

13. Abdel-Halim, S.H.; Shehata, A.M.A.; El-Shahat, M.F. Removal of lead ions from industrial waste water by different types of natural materials. Water Res. 2003, 37, 1678-1683. [CrossRef]

14. Klapiszewski, L.; Bartczak, P.; Wysokowski, M.; Jankowska, M.; Kabat, K.; Jesionowski, T. Silica conjugated with kraft lignin and its use as a novel 'green' sorbent for hazardous metal ions removal. Chem. Eng. J. 2015, 260, 684-693. [CrossRef]

15. Fang, R.; Tian, W.M.; Chen, X.B.A. Synthesis of injectable alginate hydrogels with muscle-derived stem cells for potential myocardial infarction repair. Appl. Sci. 2017, 7, 252. [CrossRef]

16. Lakouraj, M.M.; Mojerlou, F.; Zare, E.N. Nanogel and superparamagnetic nanocomposite based on sodium alginate for sorption of heavy metal ions. Carbohydr. Polym. 2014, 106, 34-41. [CrossRef]

17. Wang, Z.Q.; Huang, Y.G.; Wang, M.; Wu, G.H.; Geng, T.M.; Zhao, Y.G.; Wu, A.G. Macroporous calcium alginate aerogel as sorbent for $\mathrm{Pb}^{2+}$ removal from water media. J. Environ. Chem. Eng. 2016, 4, 3185-3192. [CrossRef]

18. Godiya, C.B.; Cheng, X.; Li, D.W.; Chen, Z.; Lu, X.L. Carboxymethyl cellulose/polyacrylamide composite hydrogel for cascaded treatment/reuse of heavy metal ions in wastewater. J. Hazard. Mater. 2019, 364, $28-38$. [CrossRef]

19. Moreno-Sader, K.; Garcia-Padilla, A.; Realpe, A.; Acevedo-Morantes, M.; Soares, J.B.P. Removal of heavy metal water pollutants $\left(\mathrm{Co}^{2+}\right.$ and $\left.\mathrm{Ni}^{2+}\right)$ using polyacrylamide/sodium montmorillonite (pam/na-mmt) nanocomposites. ACS Omega 2019, 4, 10834-10844. [CrossRef]

20. Park, H.G.; Kim, T.W.; Chae, M.Y.; Yoo, I.K. Activated carbon-containing alginate adsorbent for the simultaneous removal of heavy metals and toxic organics. Process Biochem. 2007, 42, 1371-1377. [CrossRef]

21. Unnithan, M.R.; Vinod, V.P.; Anirudhan, T.S. Synthesis, characterization, and application as a chromium(VI) adsorbent of amine-modified polyacrylamide-grafted coconut coir pith. Ind. Eng. Chem. Res. 2004, 43, 2247-2255. [CrossRef]

22. Pan, L.H.; Wang, Z.Q.; Zhao, X.Q.; He, H.Y. Efficient removal of lead and copper ions from water by enhanced strength-toughness alginate composite fibers. Int. J. Biol. Macromol. 2019, 134, 223-229. [CrossRef] [PubMed]

23. Wang, Z.Q.; Jin, P.X.; Wang, M.; Wu, G.H.; Sun, J.Y.; Zhang, Y.J.; Dong, C.; Wu, A.G. Highly efficient removal of toxic $\mathrm{Pb}^{2+}$ from wastewater by an alginate-chitosan hybrid adsorbent. J. Chem. Technol. Biotechnol. 2018, 93, 2691-2700. [CrossRef]

24. Yang, J.; Wu, J.X.; Lu, Q.F.; Lin, T.T. Facile preparation of lignosulfonate-graphene oxide-polyaniline ternary nanocomposite as an effective adsorbent for $\mathrm{Pb}(\mathrm{II})$ ions. ACS Sustain. Chem. Eng. 2014, 2, 1203-1211. [CrossRef]

25. Sprynskyy, M.; Buszewski, B.; Terzyk, A.P.; Namiesnik, J. Study of the selection mechanism of heavy metal $\left(\mathrm{Pb}^{2+}, \mathrm{Cu}^{2+}, \mathrm{Ni}^{2+}\right.$, and $\left.\mathrm{Cd}^{2+}\right)$ adsorption on clinoptilolite. J. Colloid Interf. Sci. 2006, 304, 21-28. [CrossRef]

26. Sharma, P.; Singh, A.K.; Shahi, V.K. Selective adsorption of Pb(II) from aqueous medium by cross-linked chitosan-functionalized graphene oxide adsorbent. ACS Sustain. Chem. Eng. 2019, 7, 1427-1436. [CrossRef]

27. Wang, C.P.; Wu, J.Z.; Sun, H.W.; Wang, T.; Liu, H.B.; Chang, Y. Adsorption of Pb(II) ion from aqueous solutions by tourmaline as a novel adsorbent. Ind. Eng. Chem. Res. 2011, 50, 8515-8523. [CrossRef]

28. Zhou, G.Y.; Luo, J.M.; Liu, C.B.; Chu, L.; Ma, J.H.; Tang, Y.H.; Zeng, Z.B.; Luo, S.L. A highly efficient polyampholyte hydrogel sorbent based fixed-bed process for heavy metal removal in actual industrial effluent. Water Res. 2016, 89, 151-160. [CrossRef] 
29. Googerdchian, F.; Moheb, A.; Emadi, R.; Asgari, M. Optimization of $\mathrm{Pb}(\mathrm{II})$ ions adsorption on nanohydroxyapatite adsorbents by applying taguchi method. J. Hazard. Mater. 2018, 349, 186-194. [CrossRef]

30. Rathour, R.K.S.; Bhattacharya, J.; Mukherjee, A. Facile synthesis of graphene oxide for multicycle adsorption of aqueous $\mathrm{Pb}^{2+}$ in the presence of divalent cations and polyatomic anions. J. Chem. Eng. Data 2018, 63, 3465-3474. [CrossRef]

31. Sheshmani, S.; Nematzadeh, M.A.; Shokrollahzadeh, S.; Ashori, A. Preparation of graphene oxide/chitosan/FeOOH nanocomposite for the removal of $\mathrm{Pb}(\mathrm{II})$ from aqueous solution. Int. J. Biol. Macromol. 2015, 80, 475-480. [CrossRef]

32. Yari, M.; Norouzi, M.; Mahvi, A.H.; Rajabi, M.; Yari, A.; Moradi, O.; Tyagi, I.; Gupta, V.K. Removal of Pb(II) ion from aqueous solution by graphene oxide and functionalized graphene oxide-thiol: Effect of cysteamine concentration on the bonding constant. Desalin. Water Treat. 2016, 57, 11195-11210. [CrossRef]

33. Gao, T.T.; Yu, J.G.; Zhou, Y.; Jiang, X.Y. The synthesis of graphene oxide functionalized with dithiocarbamate group and its prominent performance on adsorption of lead ions. J. Taiwan Inst. Chem. E 2017, 71, 426-432. [CrossRef]

34. Wang, N.N.; Xu, X.J.; Li, H.Y.; Zhai, J.L.; Yuan, L.Z.; Zhang, K.X.; Yu, H.W. Preparation and application of a xanthate-modified thiourea chitosan sponge for the removal of $\mathrm{Pb}(\mathrm{II})$ from aqueous solutions. Ind. Eng. Chem. Res. 2016, 55, 4960-4968. [CrossRef]

35. Wang, H.Y.; Gao, B.; Wang, S.S.; Fang, J.; Xue, Y.W.; Yang, K. Removal of Pb(II), Cu(II), and Cd(II) from aqueous solutions by biochar derived from $\mathrm{KMnO}_{4}$ treated hickory wood. Bioresour. Technol. 2015, 197, 356-362. [CrossRef] [PubMed]

36. Tan, Y.; Wang, K.L.; Yan, Q.; Zhang, S.F.; Li, J.Z.; Ji, Y. Synthesis of amino-functionalized waste wood flour adsorbent for high-capacity $\mathrm{Pb}(\mathrm{II})$ adsorption. ACS Omega 2019, 4, 10475-10484. [CrossRef] [PubMed]

37. Huang, X.M.; Pan, M. The highly efficient adsorption of $\mathrm{Pb}(\mathrm{II})$ on graphene oxides: A process combined by batch experiments and modeling techniques. J. Mol. Liq. 2016, 215, 410-416. [CrossRef]

38. Medina, R.P.; Nadres, E.T.; Ballesteros, F.C.; Rodrigues, D.F. Incorporation of graphene oxide into a chitosan-poly(acrylic acid) porous polymer nanocomposite for enhanced lead adsorption. Environ. Sci-Nano 2016, 3, 638-646. [CrossRef]

39. Mahfooz-ur-Rehman; Rehman, W.; Waseem, M.; Shah, B.A.; Shakeel, M.; Haq, S.; Zaman, U.; Bibi, I.; Khan, H.D. Fabrication of titanium-tin oxide nanocomposite with enhanced adsorption and antimicrobial applications. J. Chem. Eng. Data 2019, 64, 2436-2444. [CrossRef]

40. Kundu, S.; Chowdhury, I.H.; Naskar, M.K. Nitrogen-doped nanoporous carbon nanospheroids for selective dye adsorption and $\mathrm{Pb}(\mathrm{II})$ ion removal from waste water. ACS Omega 2018, 3, 9888-9898. [CrossRef]

41. Jin, C.; Zhang, X.Y.; Xin, J.N.; Liu, G.F.; Chen, J.; Wu, G.M.; Liu, T.; Zhang, J.W.; Kong, Z.W. Thiol-ene synthesis of cysteine-functionalized lignin for the enhanced adsorption of $\mathrm{Cu}(\mathrm{II})$ and $\mathrm{Pb}(\mathrm{II})$. Ind. Eng. Chem. Res. 2018, 57, 7872-7880. [CrossRef]

42. Bayramoglu, G.; Arica, M.Y. Mcm-41 silica particles grafted with polyacrylonitrile: Modification in to amidoxime and carboxyl groups for enhanced uranium removal from aqueous medium. Microporous Mesoporous Mater. 2016, 226, 117-124. [CrossRef]

(C) 2019 by the authors. Licensee MDPI, Basel, Switzerland. This article is an open access article distributed under the terms and conditions of the Creative Commons Attribution (CC BY) license (http://creativecommons.org/licenses/by/4.0/). 